Article

\title{
Improvement of Tubular Permanent Magnet Machine Performance Using Dual-Segment Halbach Array
}

\author{
Minh-Trung Duong ${ }^{1,2} \mathbb{D}$, Yon-Do Chun ${ }^{1,2, *}$ and Deok-Je Bang ${ }^{2}$ \\ 1 Energy and Power Conversion Engineering, University of Science and Technology, Daejeon 34113, Korea; \\ Duong.MT@keri.re.kr \\ 2 Electric Motor Research Center, Korea Electrotechnology Research Institute, Changwon 51543, Korea; \\ Djbang@keri.re.kr \\ * Correspondence: Ydchun@keri.re.kr; Tel.: +82-055-280-1490
}

Received: 15 October 2018; Accepted: 8 November 2018; Published: 13 November 2018

\begin{abstract}
In this paper, a modification of the dual-segment permanent magnet (PM) Halbach array is investigated to improve the performance of the tubular linear machine, in terms of flux density and output power. Instead of a classical Halbach array with only radial and axial PMs, the proposed model involves the insertion of mig-magnets, which have a magnetized angle shifted from the reference magnetized angles of axial and radial PMs. This structure leads to the elimination of flux leakage and the concentration of flux linkage in middle of the coil; therefore, the output power is increased by $13.2 \%$.
\end{abstract}

Keywords: electromagnetic shock absorber; tubular machine; energy harvesting; Halbach array

\section{Introduction}

Tubular machines are commonly applied in many industrial applications, such as cryocoolers, linear compressors, or refrigerators [1-3]. Recent research activities for energy harvesting in vehicle suspension systems [4-6] or using ocean wave energy [7-9] have proposed a new trend for tubular machines. From a design viewpoint, at a particular volume, increasing the output power is very difficult. L. Zou et al. [10] provide the original design, which is composed of one magnet layer using a Halbach arrangement instead of only axial magnet or radial magnet arrays. In the following step, by using the same Halbach array structure, $X$. Tang et al. [11] modified the original model with a double layer of permanent magnet; this method eliminates the flux leakage, while concentrating flux density in the middle of the coil. This leads to an eightfold improvement in the output power and a 3.8-fold improvement in the power density compared to the values of the original design.

Another technique was studied by Y. Shen, in which mid-magnets whose magnetization angle is shifted from the reference angle of axial and radial magnets are inserted [12]. There are two possible structures-odd-segment and even-segment-and these structures define the number of magnet segments over a pole pitch as an odd or even number. The FEM and analytical results for a 12-slot/10-pole PM brushless machine illustrate that the 3-segment Halbach array exhibits significantly higher fundamental airgap flux density than that of the magnet cylinder, having a traditional Halbach array with two segments. Under the same theory, W. Zhao designed a tubular linear generator for energy harvesting from body motion [13] using an even-segment Halbach array. The eight-segment dual Halbach array is employed in the optimized generator because its magnetic flux density is greater than that of the four-segment array. However, the effects of the odd-segment model were not presented.

In this paper, an electromagnetic shock absorber for vehicle energy harvesting using a segment-magnet Halbach array is proposed. Unlike most conventional research $[6,7]$, in which a mechanical shock absorber is replaced with an electrical one, the proposed device is a combination 
of both parts. Electrical components including a magnetic core, winding, and permanent magnet (PM) are attached to the inner and outer frame of the mechanical shock absorber. To validate with the corresponding experiments, a single PM layer, with a coreless model, is designed, fabricated and tested. To avoid the noise caused by the mechanism, experiments are carried out under lower vibration speeds than those of the previous study $[14,15]$. In addition, the effects of both the evenand odd-segment PM on the tubular generator are investigated and compared with the conventional one. In previous publications, these effects have mostly been investigated for rotating machine. Finite element analysis (FEA) results show thata under the same operating conditions, a tubular generator using segment-magnet yields has higher power than that of a generator with the original Halbach array structure by $13.2 \%$. In the further study, the optimized dimensions of the PM segments, the magnetized angle, and feasibility will be taken into account.

\section{Tubular Machine with Classical Halbach Array}

\subsection{Design Specifications}

This section deals with the design specifications of the tubular machine using the classical Halbach array based on the actual dimensions of a commercial shock absorber in an SUV-Korando car. Analyses using FEM are validated with corresponding experiments.

Figure 1 shows the cross-section of the half model and its geometry over one pole pitch, as was presented in Reference $[14,15]$. The overlapping length of the magnet array and coil windings is about $200 \mathrm{~mm}$ but, fortunately, this value is adjustable by $\pm 40 \mathrm{~mm}$. That is also the condition for the outer diameter, which can be flexibly chosen at values between $80 \mathrm{~mm}$ and $160 \mathrm{~mm}$, while the inner diameter has to be at least $40 \mathrm{~mm}$, the same as the diameter of the damping part or the mechanical part $[14,15]$.

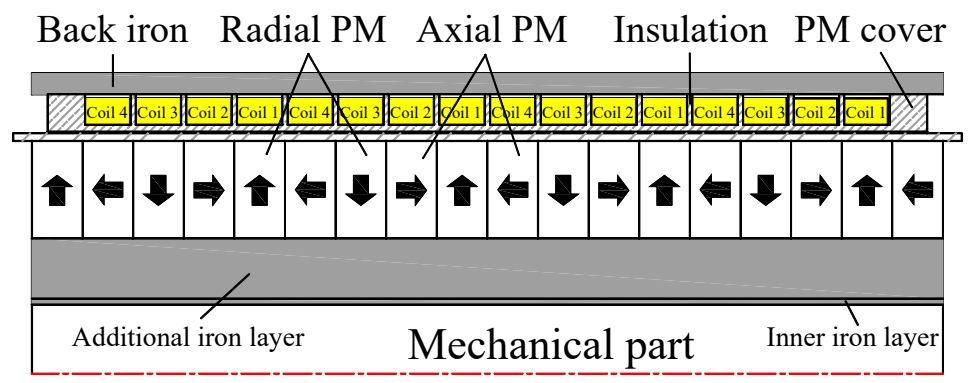

(a)

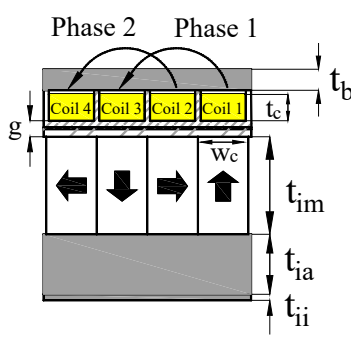

(b)

Figure 1. (a,b) Half cross-section of the single PM layer coreless model.

Due to the relative position between the coils and the excited flux density, and with the aim of simplifying the drive system, an external circuit is designed with two phases, in which phase 1 is in series connection with coil 1 and coil 3, and phase 2 is in series connection with coil 2 and coil 4. It is mandatory to precisely set up the winding directions to achieve maximum power $[14,15]$. Detailed specifications of the tubular machine are summarized in Table 1. 
Table 1. Design specifications of the tubular machine with classical Halbach array.

\begin{tabular}{lc}
\hline \multicolumn{1}{c}{ Item } & Value \\
\hline Vibration speed $(\mathrm{m} / \mathrm{s})$ & 0.25 \\
Vibration frequency $(\mathrm{Hz})$ & 10 \\
Stroke length $(\mathrm{mm})$ & 11.25 \\
Length, $\mathrm{L}(\mathrm{mm})$ & 243 \\
Outer diameter, $\mathrm{D}(\mathrm{mm})$ & 160 \\
PM thickness, $\mathrm{t}_{\mathrm{im}}(\mathrm{mm})$ & 26.0 \\
Radial PM width, $\mathrm{w}_{\mathrm{rm}}(\mathrm{mm})$ & 13.5 \\
Axial PM width, $\mathrm{w}_{\mathrm{am}}(\mathrm{mm})$ & 13.5 \\
Pole pitch, $\tau_{\mathrm{p}}(\mathrm{mm})$ & 27.0 \\
Coil window thickness, $\mathrm{t}_{\mathrm{c}}(\mathrm{mm})$ & 8.0 \\
Coil window width, $\mathrm{w}_{\mathrm{c}}(\mathrm{mm})$ & 12.1 \\
Mechanical air gap, $(\mathrm{mm})$ & 4.3 \\
Inner iron thickness, $\mathrm{t}_{\mathrm{ii}}(\mathrm{mm})$ & 1.6 \\
Added iron thickness, $\mathrm{t}_{\mathrm{i}}(\mathrm{mm})$ & 16.0 \\
Back iron thickness, $\mathrm{t}_{\mathrm{b}}(\mathrm{mm})$ & 5.6 \\
Wire diameter, $\mathrm{w}_{\mathrm{r}}(\mathrm{mm})$ & 0.6 \\
Number of winding $/ \mathrm{slot}, \mathrm{turns}$ & 180 \\
Number of poles, $\mathrm{N}_{\mathrm{p}}$ & 8 \\
Number of slots, $\mathrm{N}_{\mathrm{s}}$ & 16 \\
Back iron material & $\mathrm{S} 20 \mathrm{C}$ \\
PMs material & $\mathrm{NdFeB}-\mathrm{N} 40 \mathrm{SH} ; \mathrm{B}_{\mathrm{r}}=1.26 \mathrm{~T}\left(\mathrm{at} 2{ }^{\circ} \mathrm{C}\right) ; \mu_{\mathrm{r}}=1.05$ \\
\hline
\end{tabular}

The relative position between the coils and the excited flux, and the external circuit, are shown in the Figure 2. According to References [10,14,16], the maximum output power occurs at the maximum vibrating speed $v_{\max }$ when the load resistance $R_{L}$ equals the sum of the coil resistance $R_{c}$; this is termed the full load condition.

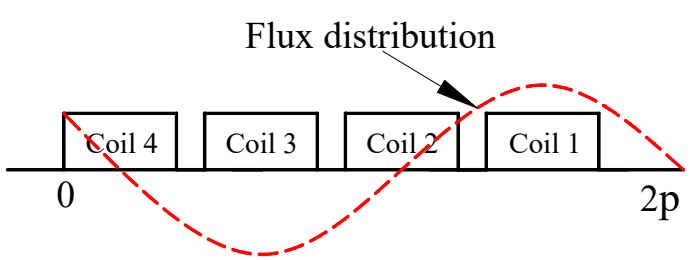

(a)

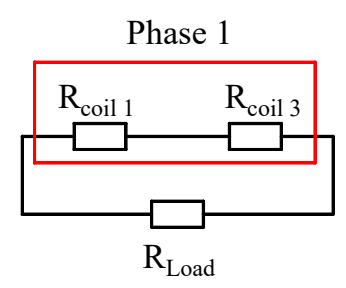

(b)

Figure 2. (a) Coils and excited flux density; (b) External circuit.

Equation (1) shows that output power is proportional to the square of the radial flux density, the square of the vibrating speed and the volumes of the coil $[10,14,15]$.

$$
\mathrm{P}_{\max }=\mathrm{V}_{\mathrm{e}} \mathrm{I}_{0}=\mathrm{B}_{\mathrm{r}}^{2} \mathrm{v}_{\mathrm{Z}}^{2} \sigma \mathrm{V}_{\text {coil }}
$$

where $B_{r}$ is the radial flux density, $v_{z}$ is the vibrating speed, $\sigma$ is the conductivity, and $V_{\text {coil }}$ is the coil volume.

The relationship between the peak to peak stroke, the vibrating speed, and the vibrating frequency is calculated as follows $[10,14,15]$ :

$$
\text { Stroke }_{\text {peak-to-peak }}=\frac{\mathrm{v}_{\max }}{\omega}=\frac{\mathrm{v}_{\mathrm{rms}} \sqrt{2}}{\pi \mathrm{f}}
$$

where $v_{r m s}$ is root-mean-square of the vibration speed, and $f$ is the vibration frequency.

In addition, the instantaneous voltage of one coil centered at equilibrium position $\mathrm{z}_{0}$ in the regenerative shock absorber is presented as a function of time, position, magnetic flux density $B_{0}$, 
length of the conductor $\mathrm{L}$, sum of the thicknesses $\mathrm{H}$ of a radial and an axial PM, suspension velocity and frequency. For the $0^{\circ}$ coil or for coil 1 , which has the maximum magnetic flux density, if the vibration amplitude is small, the voltage is calculated by [10]:

$$
\mathrm{V}_{0^{\circ}}=\mathrm{B}_{0} \mathrm{~L}\left|\frac{\mathrm{j} \omega}{\omega_{\mathrm{n}}^{2}-\omega^{2}+2 \mathrm{j} \zeta \omega_{\mathrm{n}} \omega} \mathrm{e}_{\mathrm{in}}\right| \sin \omega \mathrm{t}
$$

and a $90^{\circ}$ coil or coil 3 will have a double frequency wave [10]:

$$
\mathrm{V}_{90^{\circ}}=\mathrm{B}_{0} \mathrm{~L} \frac{\pi \mathrm{V}_{\max }^{2}}{2 \mathrm{H} \omega} \sin 2 \omega \mathrm{t}
$$

The additional iron layer is inserted to reduce the inner diameter of the PMs; this layer is composed of stainless steel, while the back iron is made of an electromagnetic material. Both radial PMs and axial PMs are made of DDP-40SH, which has a relative flux density of $\mathrm{B}_{\mathrm{r}}=1.26 \mathrm{~T}$ at $20^{\circ} \mathrm{C}$ and a relative permeability of $\mu_{\mathrm{r}}=1.05$. Windings are wound around and supported by a bobbin with a total number of turns per slot of 180 .

\subsection{Validation with Experimental Data}

According to Reference [10], when a mid-sized car is moving at a speed of $60 \mathrm{mph}$ on a road class $C$, the vibrating frequency of the shock absorber is estimated to be approximately $0.25 \mathrm{~m} / \mathrm{s}$. Under these conditions, the peak to peak stroke length and vibrating frequency are about $11.25 \mathrm{~mm}$ and $10 \mathrm{~Hz}$, respectively. These conditions of the stroke length, vibrating speed, and linear frequency are considered as a standard for the models studied in this paper. When applying the standard conditions, the maximum and average power can be theoretically calculated as $76.09 \mathrm{~W}$ and $37.8 \mathrm{~W}$, respectively.

To prepare for the experiments, a prototype of a single layer coreless model was fabricated and installed, as in the illustrations provided in Figures 3 and 4. Unfortunately, if the linear frequency of the generator is $10 \mathrm{~Hz}$, the required rotating speed of the sub-motor is $3000 \mathrm{rpm}$, which exceeds the limitation of this motor; therefore, measurements were performed at lower vibrating speeds than in the previous study $[14,15]$.

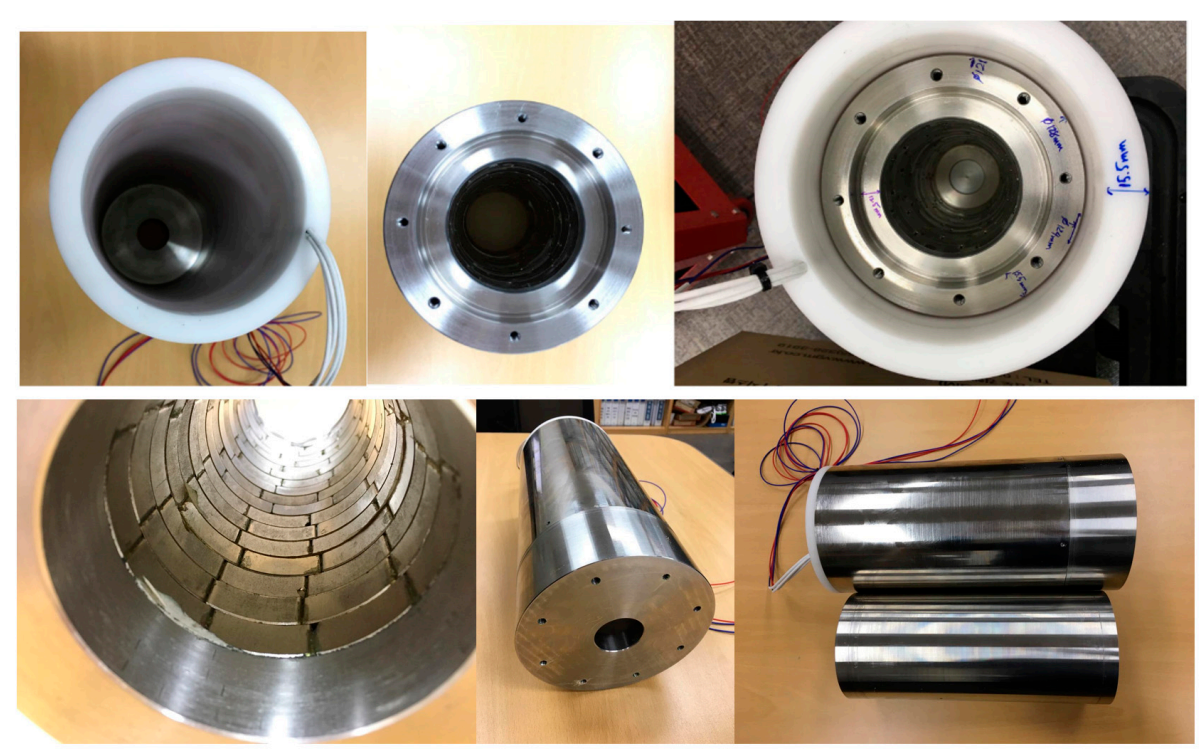

Figure 3. Prototype. 

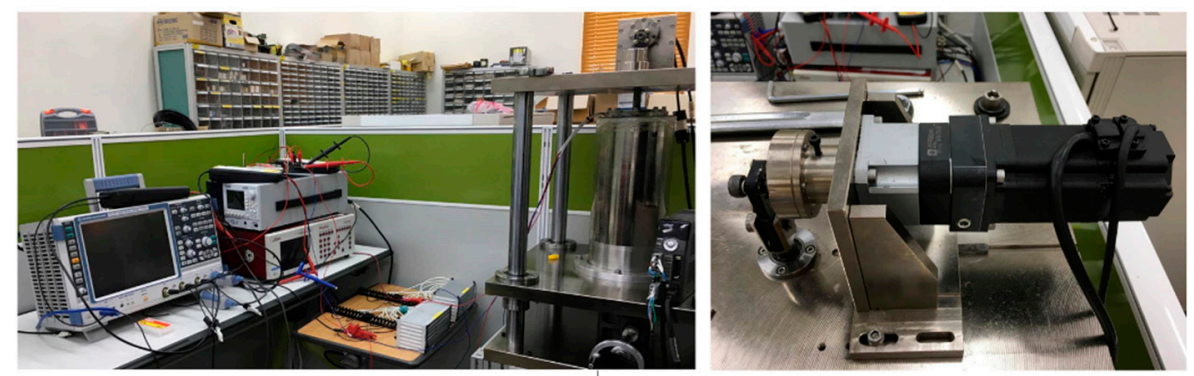

Figure 4. Experimental installment.

Figure 5 shows the mesh elements generated from Flux 2D, a commercial FEA software. There are 26,182 nodes, 2607 line elements and 13,601 surface elements. In addition, the number of excellent quality elements is $99.1 \%$.

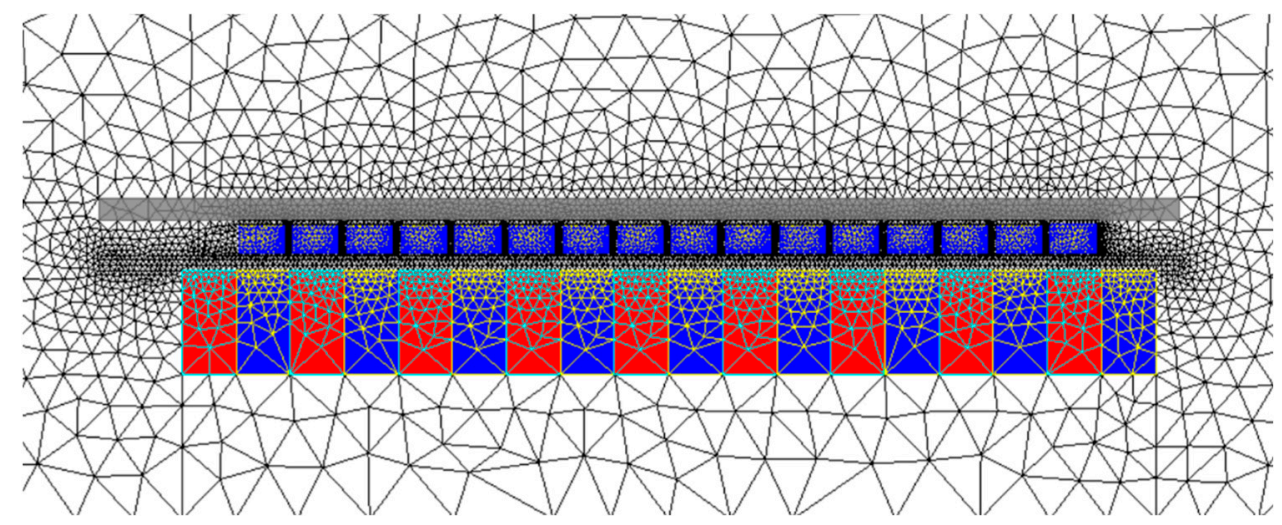

Figure 5. Surface mesh elements in the 2D FEA analysis.

With the assumption that the peak to peak stroke length is fixed at $11.25 \mathrm{~mm}$, Figure 6 presents the back EMF waveforms achieved for the load resistance when the vibrating speed is $0.125 \mathrm{~m} / \mathrm{s}$, which equals $50 \%$ of the standard. The average deviation is approximately $6.7 \%$. In Figure $6 \mathrm{~b}$, it can be clearly seen that the frequency of load 2 is double that of load 1 ; this phenomenon can be predicted using Equations (3) and (4).

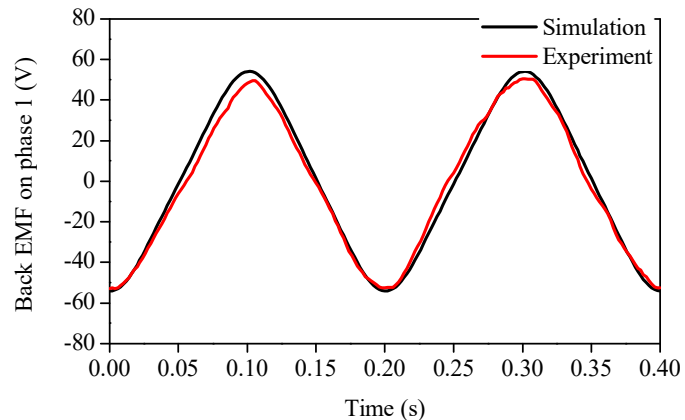

(a)

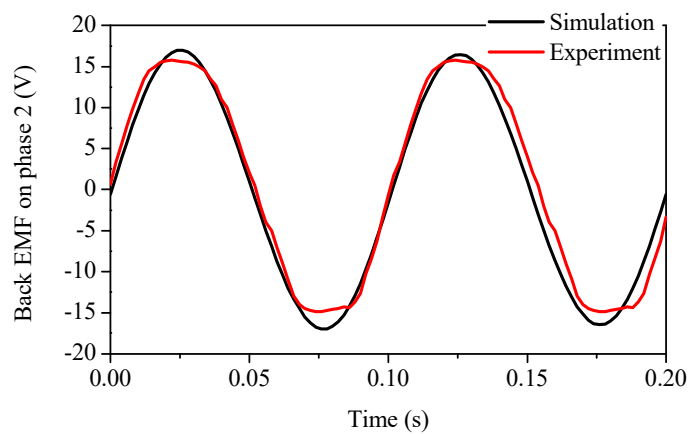

(b)

Figure 6. Comparison of the back EMF on the load resistors obtained from the FEA and experiment under a vibrating speed of $0.125 \mathrm{~m} / \mathrm{s}$ : (a) Phase 1; (b) Phase 2.

Figure 7 illustrates the power variation according to various vibrating speeds under the full load condition. While the maximum output voltage is well-matched between the analyses and the experiments, with an average deviation of only $4.8 \%$, the results of the average output power are not 
very satisfactory, being around $13.5 \%$. Although the resistance in one phase under full load condition is measured at nearly $39.3 \Omega$, in the experimental setup, only $39 \Omega$ of the load resistance can be connected.

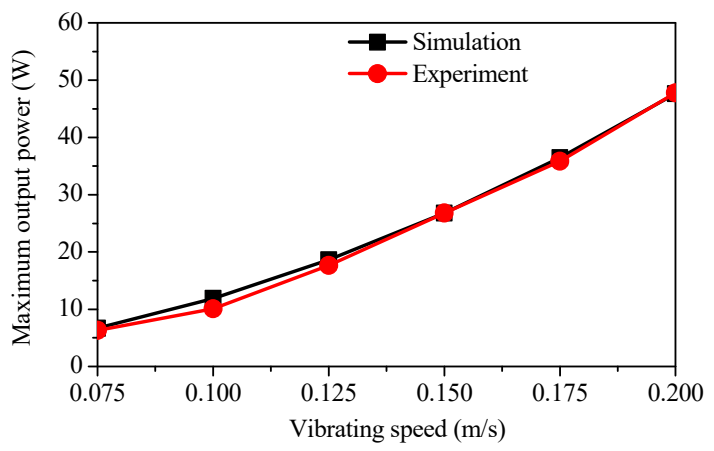

(a)

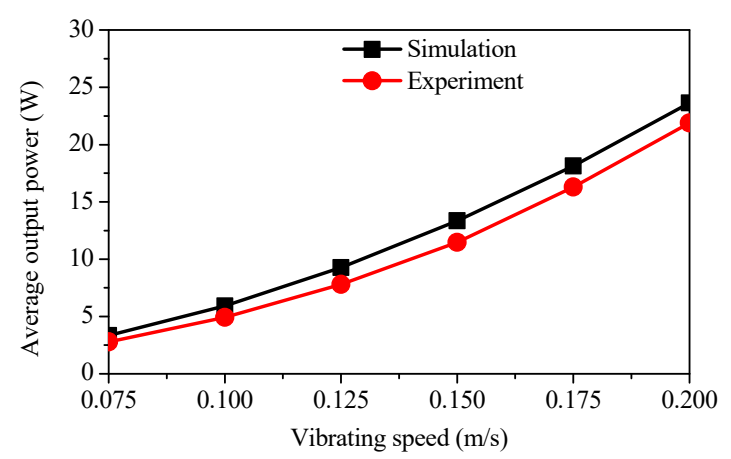

(b)

Figure 7. Power variation according to vibrating speeds under full load condition: (a) maximum output power; (b) average output power.

Another noticeable phenomenon is the linear relationship between the output power and the square of the vibrating speed, according to Equation (1). For instance, when the generator is operating at $0.075 \mathrm{~m} / \mathrm{s}$, an average power of about $2.78 \mathrm{~W}$ can be obtained. The average power under a vibrating speed of $0.15 \mathrm{~m} / \mathrm{s}$ can be predicted according to the following equation:

$$
\mathrm{P}_{0.15 \mathrm{~m} / \mathrm{s}}=\mathrm{P}_{0.075 \mathrm{~m} / \mathrm{s}} \times\left(\frac{0.15}{0.075}\right)^{2}=2.78 \times\left(\frac{0.15}{0.075}\right)^{2} \approx 11.12(\mathrm{~W})
$$

The measured result at a vibrating speed of $0.15 \mathrm{~m} / \mathrm{s}$ for the average power is approximately $11.46 \mathrm{~W}$, which is nearly the same as the expectation.

Figure 8 illustrates the power variation according to various load resistances when the vibrating speed is $0.125 \mathrm{~m} / \mathrm{s}$ and the peak to peak stroke length is $11.25 \mathrm{~mm}$. Both the analysis and the experiment results present similar trends, with an average deviation of about $13.4 \%$. When the load resistance equals the sum of the coil resistance, the average output power is at its maximum. There are several possible explanations for the differences between the simulation and the experiment in Figures 6-8. As illustrated in Figure 3, owing to the limitations during manufacturing, the permanent magnets were separated into smaller segments of a solid toroidal shape. Moreover, when the prototype is being measured, errors can occur due to the noise caused by the mechanical system. However, the accuracy is much better than the previous design for the coreless model.

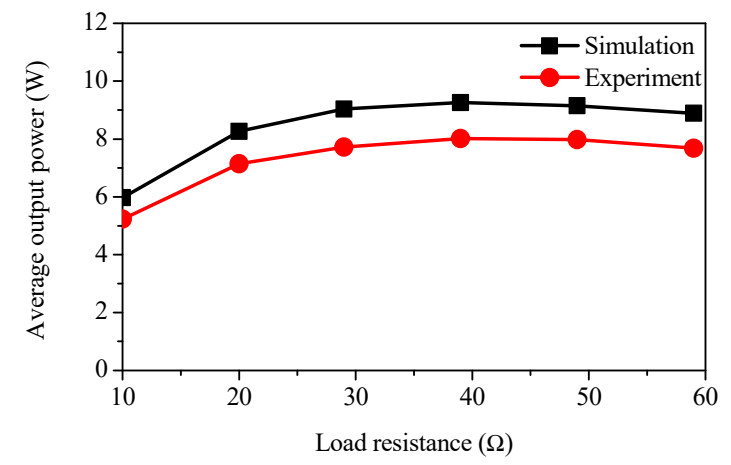

Figure 8. Average power according to various load resistances. 


\section{Tubular Machine with Dual-Segment Halbach Array}

In this section, a dual-segment Halbach array is applied to the same tubular generator with the aim of improving the output power. The design specifications with the number of magnets, the sizes, and the magnetized direction are shown in Figure 9 and Table 2.

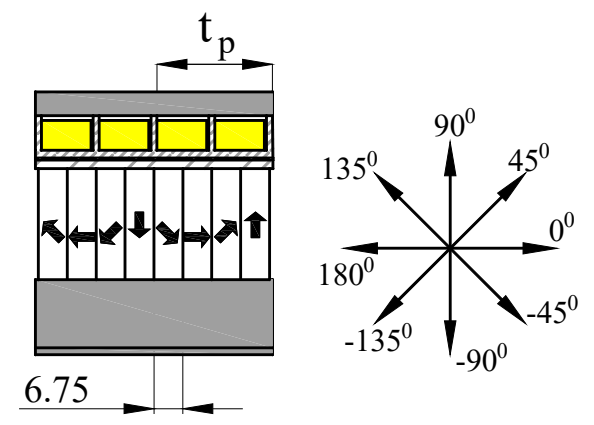

(a)

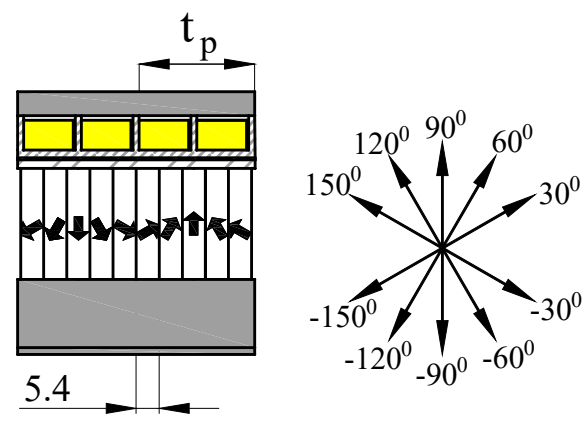

(b)

Figure 9. (a) 4-segment Halbach array; (b) 5-segment Halbach array.

Table 2. Specifications of the magnet segments over one pole pitch.

\begin{tabular}{|c|c|c|c|}
\hline Item & Classical Halbach Array & 4-Segment & 5-Segment \\
\hline Vibration speed (m/s) & & 0.25 & \\
\hline Vibration frequency $(\mathrm{Hz})$ & & 10 & \\
\hline Stroke length (mm) & & 11.25 & \\
\hline Length (mm) & & 243 & \\
\hline Diameter $(\mathrm{mm})$ & & 160 & \\
\hline Pole pitch, $\tau_{\mathrm{p}}(\mathrm{mm})$ & & 27 & \\
\hline Number of segments/pole pitch & 2 & 4 & 5 \\
\hline Width of each segment (mm) & 13.5 & 6.75 & 5.4 \\
\hline $\begin{array}{l}\text { Magnetized angle of } \\
\text { mid-magnet }\end{array}$ & - & $45^{\circ}$ & $30^{\circ}$ \\
\hline
\end{tabular}

Based on the results in Reference [12], instead of applying only axial and radial PMs over one pole pitch in a classical Halbach array, a number of mid-magnets with different magnetized angles are inserted. There are two applicable approaches: even-segment, with an even number of magnets over one pole pitch, and odd-segment, with an odd number of magnets over one pole pitch. In the original design, the pole pitch is $\tau_{\mathrm{p}}=27 \mathrm{~mm}$, so the number of PM segments is selected to be 4 in the even-segment case and 5 in the odd-segment case. If there is a higher number of segments, the width of each segment becomes smaller. In the case of the odd-segment, the axial PM with $0^{\circ}$ of the magnetized angle is removed [8]. For a fair comparison, the other dimensions, such as the length and diameter of the generator, the number of turns per slot, and the materials, are the same for the 3 models. In addition, in the preliminary investigation, the magnetized angle is equally divided.

Figure 10 shows the flux distribution on the 3 different models under a no-load condition, with a vibrating speed of $0.25 \mathrm{~m} / \mathrm{s}$, a peak to peak stroke length of $11.25 \mathrm{~mm}$ and a linear speed of $10 \mathrm{~Hz}$. According to Equation (1), the output power is proportional to the radial flux density in the middle of the coil. In the cases of the 4-segment and 5-segment magnet, the radial flux density increased by $6.8 \%$ and $5.2 \%$, respectively; therefore, the output power can be expected to increase by around $15 \%$. Due to the absence of the axial PM $\left(0^{\circ}\right.$ of the magnetized angle), the flux linkage in the odd-segment PM model is slightly higher than that of the even-segment PM model. Figure 11 presents a comparison of the three models in terms of the radial flux density in the middle of the coil and the output power. The other characteristics are summarized in Table 3. 


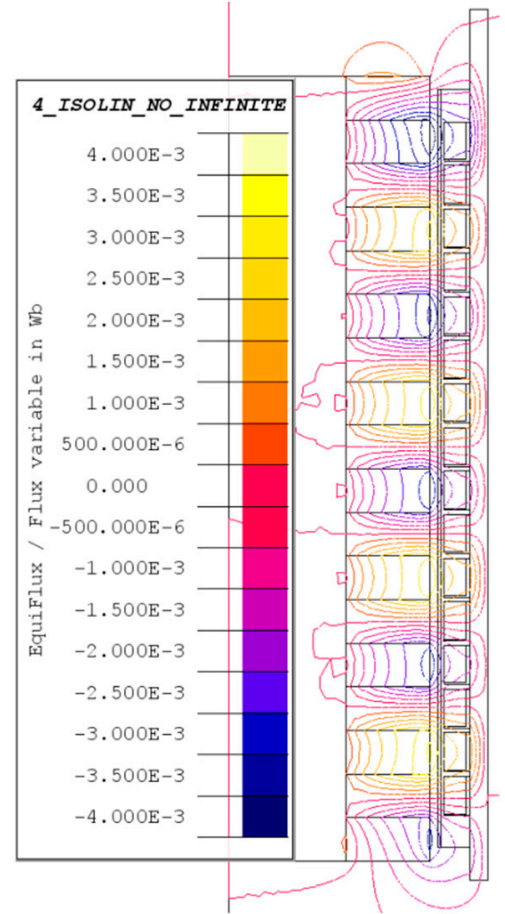

(a)

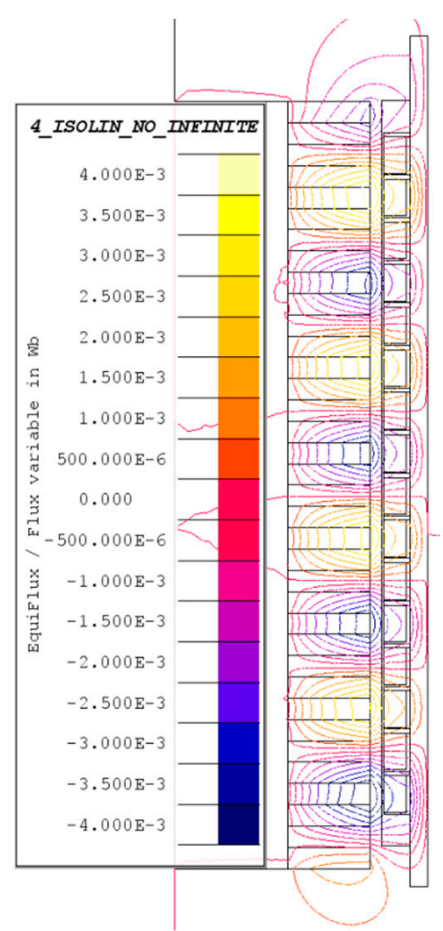

(b)

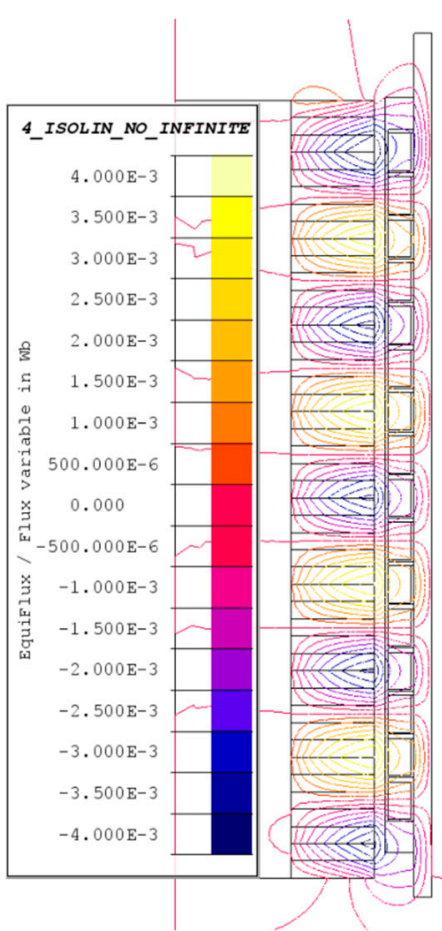

(c)

Figure 10. Flux distribution on the three different models under no-load condition: (a) classical Halbach array; (b) 4-segment; (c) 5-segment.

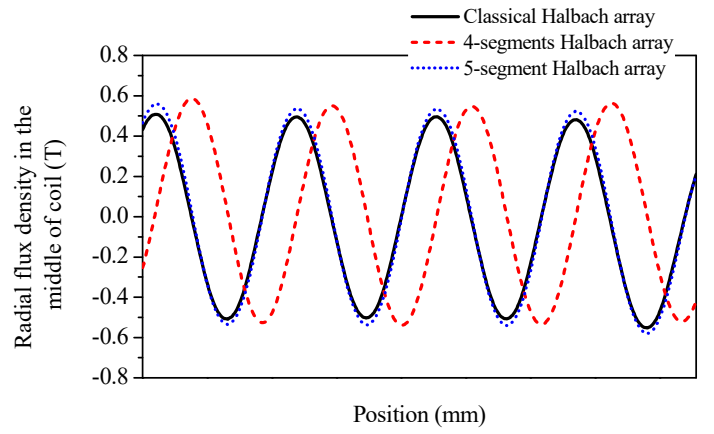

(a)

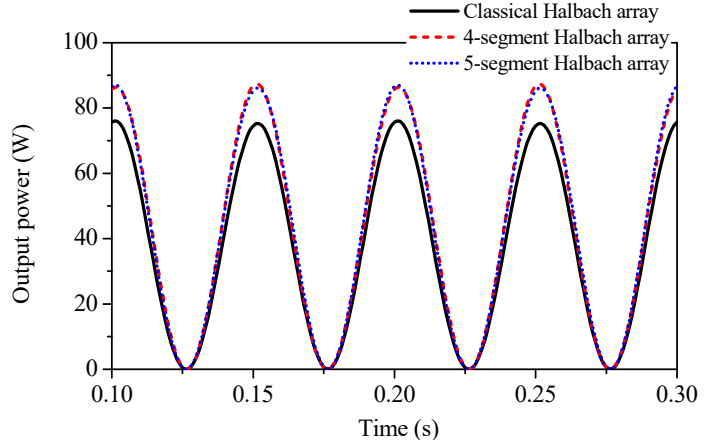

(b)

Figure 11. Comparison of: (a) 4-segment Halbach array; (b) 5-segment Halbach array.

Table 3. Comparison of three models.

\begin{tabular}{lcccc}
\hline \multicolumn{1}{c}{ Items } & & Classical Halbach Array & 4 Segment & 5 Segment \\
\hline \multirow{2}{*}{ Radial flux density (T) } & Max & 0.55 & 0.59 & 0.58 \\
& RMS & 0.36 & 0.39 & 0.39 \\
\hline Maximum induced & Phase 1 & 54.10 & 57.98 & 57.86 \\
voltages (V) & Phase 2 & 17.05 & 18.53 & 19.12 \\
\hline \multirow{2}{*}{ Output Power (W) } & Maximum & 76.09 & 87.10 & 87.38 \\
& Average & 37.78 & 43.53 & 43.47 \\
\hline
\end{tabular}

\section{Conclusions}

In this paper, a tubular permanent magnet machine composed of a novel magnet arrangement is proposed and compared with the conventional model in terms of the radial flux density in the middle of the coil and output power. A prototype of a tubular machine composed of the classical Halbach 
array was fabricated and validated using the FEM analyzed results, which show an average deviation of $13.5 \%$ in terms of the output power.

Unlike devices that use the classical Halbach array, in the proposed model mid-magnets are inserted, which have a magnetized direction that is shifted from that of the original axial and radial PMs. Based on the FEM analyses, in the cases of 4-segment and 5-segment Halbach arrays, the RMS values of the radial flux density increased by nearly $6.8 \%$, which led to an increase in the average output power of $13.2 \%$.

In a further study, the relative dimensions and the magnetized angle between the magnet segments will be optimized.

Author Contributions: Investigation, M.-T.D.; Writing-Review \& Editing, M.-T.D.; Supervision, Y.-D.C.; Project Administration, D.-J.B.

Acknowledgments: This research was supported by the KERI Primary research program of MSIT/NST (No. 18-12-N0102-04).

Conflicts of Interest: The authors declare no conflict of interest.

\section{References}

1. Li, K.; Zhang, X.; Chen, H. Design Optimization of a Tubular Permanent Magnet Machine for Cryocoolers. IEEE Trans. Magn. 2015, 51, 1-8. [CrossRef]

2. Wang, J.; Lin, Z.; Howe, D. Analysis of a short-stroke, single-phase, quasi-Halbach magnetised tubular permanent magnet motor for linear compressor applications. IET Electr. Power Appl. 2008, 2, 193-200. [CrossRef]

3. Wang, J.; Howe, D.; Lin, Z. Design Optimization of Short-Stroke Single-Phase Tubular Permanent-Magnet Motor for Refrigeration Applications. IEEE Trans. Ind. Electron. 2010, 57, 327-334. [CrossRef]

4. Shen, Y.; Lu, Q.; Ye, Y. Double-Stator Air-Core Tubular Permanent Magnet Linear Motor for Vehicle Active Suspension Systems. In Proceedings of the 2016 IEEE Vehicle Power and Propulsion Conference (VPPC), Hangzhou, China, 17-20 October 2016; pp. 1-6.

5. Abdelkareem, M.A.A.; Xu, L.; Ali, M.K.A.; Elagouz, A.; Mi, J.; Guo, S.; Liu, Y.; Zuo, L. Vibration energy harvesting in automotive suspension system: A detailed review. Appl. Energy 2018, 229, 672-699. [CrossRef]

6. Zhang, R.; Wang, X.; John, S. A Comprehensive Review of the Techniques on Regenerative Shock Absorber Systems. Energies 2018, 11, 1167. Available online: https://www.mdpi.com/1996-1073/11/5/1167 (accessed on 29 October 2018). [CrossRef]

7. Cappelli, L.; Marignetti, F.; Mattiazzo, G.; Giorcelli, E.; Bracco, G.; Carbone, S.; Attaianese, C. Linear Tubular Permanent-Magnet Generators for the Inertial Sea Wave Energy Converter. IEEE Trans. Ind. Appl. 2014, 50, 1817-1828. [CrossRef]

8. Aderinto, T.; Li, H.; Aderinto, T.; Li, H. Ocean Wave Energy Converters: Status and Challenges. Energies 2018, 11, 1250. [CrossRef]

9. Xia, T.; Yu, H.; Shi, Z.; Guo, R. Comparative Analysis and Experimental Verification of a Linear Tubular Generator for Wave Energy Conversion. Energies 2018, 11, 1707. Available online: https:/ /www.mdpi.com/ 1996-1073/11/7/1707/htm (accessed on 29 October 2018). [CrossRef]

10. Design and Characterization of an Electromagnetic Energy Harvester for Vehicle Suspensions-IOPScience. Available online: http:/ /iopscience.iop.org/article/10.1088/0964-1726/19/4/045003/meta (accessed on 4 June 2018).

11. Tang, X.; Lin, T.; Zuo, L. Design and Optimization of a Tubular Linear Electromagnetic Vibration Energy Harvester. IEEE/ASME Trans. Mechatron. 2014, 19, 615-622. [CrossRef]

12. Shen, Y. Novel Permanent Magnet Brushless Machines Having Segmented Halbach Array. Ph.D. Thesis, University of Sheffield, Sheffield, UK, 2013.

13. Ma, C.; Zhao, W.; Qu, L. Design optimization of a linear generator with dual Halbach array for human motion energy harvesting. In Proceedings of the 2015 IEEE International Electric Machines Drives Conference (IEMDC), Coeur d'Alene, ID, USA, 10-13 May 2015; pp. 703-708. 
14. Duong, M.-T.; Chun, Y.-D.; Han, P.-W.; Park, B.-G.; Bang, D.-J.; Lee, J.-K. Design of An Electromagnetic Energy Harvesting System Applied to The Shock Absorber of A Sport Utility Vehicle. Available online: http:/ / www.dbpia.co.kr (accessed on 4 June 2018).

15. Duong, M.-T.; Chun, Y.-D. Design of an Electromagnetic Energy Harvesting System Applied to Shock Absorber in Sport Utility Vehicle. J. Magn. 2018, 23, 392-398. [CrossRef]

16. Goldner, R.B.; Zerigian, P. Electromagnetic Linear Generator and Shock Absorber. U.S. Patent No. 6,952,060, 4 October 2005. article distributed under the terms and conditions of the Creative Commons Attribution (CC BY) license (http://creativecommons.org/licenses/by/4.0/). 